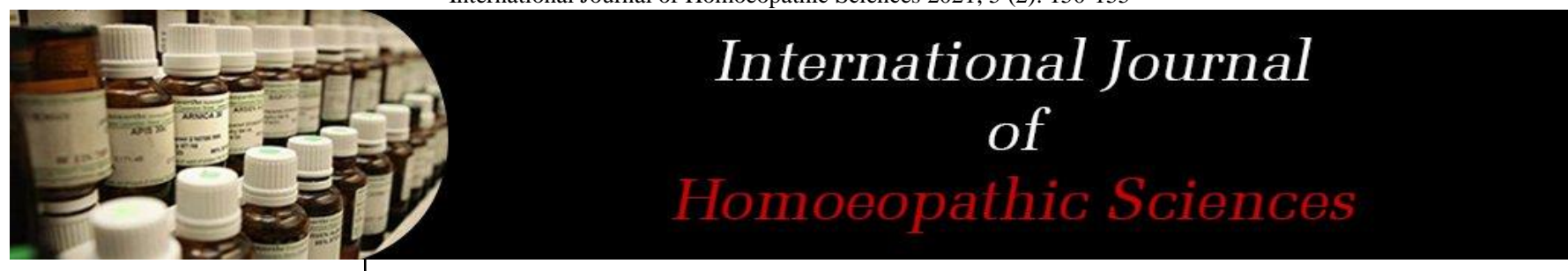

E-ISSN: $2616-4493$ P-ISSN: 2616-4485 www.homoeopathicjournal.com IJHS 2021; 5 (2): 150-155 Received: 10-01-2021 Accepted: 13-02-2021

Dr. C Vaishnavi Intern, Homoeopathic Medical College and Hospital, Chandigarh, India

\section{Dr. Tina Anand} Reader MD (HOM) Department of pathology and microbiology, Homoeopathic Medical College and Hospital, Chandigarh, India
Corresponding Author: Dr. C Vaishnavi Intern, Homoeopathic Medical College and Hospital, Chandigarh, India

\title{
Homoeopathic approach to vaginismus: One of the less reported causes of infertility
}

\section{Dr. C Vaishnavi and Dr. Tina Anand}

DOI: https://doi.org/10.33545/26164485.2021.v5.i2c.375
Abstract

This article aims at covering scope of homoeopathic constitutional treatment in cases of infertility caused by one of the under-reported entities, which leads to delayed conception not because of their untreatable nature but more as far not being discovered openly. Vaginismus, which is less reported but a cause that is more amicable to treatment. It is a state of involuntary spasmodic condition of pelvic muscle which leads to failure of penetration. This diagnosis rarely brings couples to clinics but is not as rare a cause of delayed conception. In conventional set ups vaginismus needs psychotherapy which fails to provide results in many, where homoeopathic remedies can help brings about better results when integrated with conventional treatment.

Keywords: Infertility, vaginismus, homoeopathic constitutional treatment

\section{Introduction}

Infertility is defined as the failure to give birth to a viable baby within one or more years of regular unprotected coitus.

Generally, the term 'infertility' implies on incapability for conception but by common usage it is applied to all the women who have never borne children even though it has not been established that the failure to conceive is due to their incapacity. Whereas, sterility indicates absolute inability to conceive for one or more reasons. It has been very appropriately applied to women who have a capacity for conception but who remain childless either because of the fertilizing element or because the conception occurs but the ovum does not mature. If a couple fails to achieve pregnancy after one year of unprotected and regular intercourse, it is an indication to investigate the couple. This is based on the observation that $80 \%$ of normal couples achieve conception within one year. Infertility is termed primary if conception has never occurred, and secondary if the patient fails to conceive after having achieved a previous conception?

Physiological infertility is present before puberty and after the menopause. It must be remembered however, that a girl may conceive before menstruation develops if the first ovum to be shed is fertilized but it is rare because the initial cycles are usually anovulatory. After menopause, pregnancy is very rare and nearly impossible because of the same reason that the menopausal ovaries contain no Graafian follicles. A physiological infertility during pregnancy is due to inhibition of ovulation once conception occurs. The infertility of the lactation period is regarded as relative. The time of return of ovulation and menstruation during lactation is variable and unpredictable. Two percent of non-lactating women show evidence of ovulation in the first month following delivery and 33\% ovulate before the first menstruation. The duration of amenorrhoea after the childbirth is on an average of two months but may be longer in nursing mothers. Regularly lactating women experience a longer duration of amenorrhoea and ovulation is delayed for at least three months or even longer at times.

\section{Incidence}

The incidence of female infertility is increasing day by day. According to some research studies it has come to notice that the chances of a female to conceive within the first year of regular unprotected sex are $85 \%$. According to WHO one in every four couples in developing countries had been found to be affected by infertility, approximately $8 \%-10 \%$ of couples worldwide of $60-80$ million couples suffering from infertility every year worldwide. Failure to ovulate is the most common cause of female infertility occurring in 
around $36 \%-40 \%$ of women which results from several causes in which polycystic ovarian disease is the one with highest number of cases (in almost 40 percent of cases).

\section{Causes}

The important causes of infertility (as given by FIGO manual) are tubal and peritoneal factors (25-35 percent), ovulatory factors (15-25 percent) and endometriosis (1-10 percent).

Congenital defects of the female may prevent spermatozoa from ascending to the fallopian tubes. In extreme cases the vagina is not developed at all. If the uterus fails to develop, or if it is of the fetal type without canalization, the woman must be sterile. Infertility may be caused by less severe degrees of mal-development, such as rigid hymen, elongated conical cervix with a pinhole os and acute anteflexion and retroflexion of the uterus but in these conditions the associated genital hypoplasia may be a factor in producing infertility.

One of the commonest causes of infertility is salpingitis, gonorrheal and chlamydial trachomatis infections of the fallopian tube or salpingitis following septic abortion and puerperal infection are among the common causes of infertility of this type. Tuberculosis of the tubes also causes infertility for some reasons.

A brief about the causes of female infertility are

1. Causes preventing the entrance of semen into the uterus
a. Absence of uterus or vagina
b. Obturator hymen
c. Vaginismus
d. Atresia vaginae
e. Occlusion of cervical canal
f. Conical shape of cervix
g. Cervical endometriosis
h. Polyp or fibroid
i. Displacements
j. Very small os internum

2. Causes preventing the production of healthy ovule
a. Chronic ovaritis
b. Cystic disease of both ovaries
c. Cellulitis or peritonitis
d. Absence of ovaries

3. Cause preventing passage of ovule into uterus
a. Structure or obliteration of fallopian tubes
b. Absence of fallopian tubes
c. Detachment and displacement of fallopian tubes

4. Causes destroying vitality of semen or preventing fixation of impregnated ovum
a. Corporeas or cervical endometriosis
b. Membranous dysmenorrhoea
c. Menorrhagia or metorrhagia
d. Abnormal growths
e. Chronic metritis

\section{Vaginismus}

Vaginismus is less reported but a cause that is more amicable to treatment and hence early conception. It can be regarded as a hyper-aesthesia which leads to spasm of the sphincter vagina and the levator ani muscles during attempted coitus or when an attempt is made to examine the patient vaginally. Vaginismus can lead to dyspareunia, infertility and sexual dysfunction in both partners with frequent secondary erectile dysfunction in the male partner and therefore has a severe impact on the quality of the marital relationship. It results from fear of pain and fear of intercourse, making coitus impossible or extremely difficult. This condition occurs in many unconsummated marriages.

It should be subdivided into primary vaginismus, in which there is no organic lesion present and secondary vaginismus in which some obvious painful lesion in the region of the genital tract can be found on examination.

In primary Vaginismus, when the patient is being examined in the left lateral position and an attempt is being made to inspect the vulva by separating the labia, a muscle spasm is induced whereby the thighs are drawn together, the women turns over on her back and by spasm of the muscles of her back assumes a state of mild opisthotonos. The levator muscles become tonically contracted and commonly the patient cries out and endeavours to push the medical attendant away from her.

In secondary vaginismus, a minor degree of spasm may be brought about by painful local lesions such a small infected lacerations of the hymen, urethral caruncles, and vulvitis or as a sequel of vaginal operations for repair of prolapse when as a result of the operation the caliber of the introitus and the vagina is narrowed. Removal of the cause will cure this condition whereas in true vaginismus treatment is prolonged and the result is not always satisfactory.

\section{Treatment}

Conventionally treatment of vaginismus is mostly psychological and cognitive behavioral therapy (CBT). It consists essentially of two techniques: sexual education and hierarchic exposure. Typical vaginismus always has a psychoneurotic basis. It is here that Homoeopathic constitutional treatment has been found more accepted and also effective. Frequently a history of mental trauma during adolescence can be traced and in most women with vaginismus there is a subconscious dread of sexual intercourse. If a patient is suffering from vaginismus is examined under an anaesthetic, bimanual pelvic examination will most likely reveal no organic abnormality. Occasionally the hymen is incompletely ruptured and the introitus inadequately dilated, but these findings are rare and their correction by plastic enlargement, though logical, does little to relieve the subsequent spasm since it is psychogenic rather than organic, thus more amicable to homoeopathic treatment. The repertorisation of vaginismus symptoms when studied under various repertories repeatedly indicates two drugs, Cactus grandiflorus and Platinum metallicum, thus illustrating the ability of the Materia Medica to summarize the complexity of a disease. The converging perspectives of homeopathic and gynaecological semeiologies can enrich and update medical practice. The best possible treatment plan needs to be stood on individual patient characteristics. In such cases along with counseling homoeopathic medicines help to raise the individual for normal conception. 
Rubric and sub rubric of vaginismus in various repertories are

Table 1: Repertory of homoeopathic materia medica by JT Kent

\begin{tabular}{|c|c|c|c|c|c|}
\hline Chapter & Rubric & Sub rubric & $\begin{array}{l}1^{\text {st }} \text { grade } \\
\text { remedies }\end{array}$ & $\begin{array}{l}2^{\text {nd }} \text { grade } \\
\text { remedies }\end{array}$ & $3^{\text {rd }}$ grade remedies \\
\hline \multirow[t]{5}{*}{ Female } & Vaginismus & & $\begin{array}{l}\text { Cact, cupr, ign, } \\
\text { plat, plb, staph }\end{array}$ & $\begin{array}{l}\text { Acon, bell, berb, } \\
\text { canth, caul, cimic, } \\
\text { coff, ferr-p, ham, } \\
\text { lyc, murx, nat-m, } \\
\text { pils, sil, thuj }\end{array}$ & $\begin{array}{l}\text { Aln, alumn, apis, aq-mar, arg-n, atro, aur, bor, cac, calc, } \\
\text { calc-p, carb-v, caust, coc-c, cocc, con, cupr-acet, ferr, ferr-i, } \\
\text { ferr-m, ferr-ma, gels, hep, hydr, kali-bi, kali-br, kali-c, } \\
\text { kreos, lac-c, lach, lyss, mag-p, med, merc, mur-ac, nit-ac, } \\
\text { nux-m, nux-v, orig, plumb, pop, rhus-t, Sabina, sep, sulph, } \\
\text { syph, tarent }\end{array}$ \\
\hline & & $\begin{array}{l}\text { Emaciation and } \\
\text { constipation with }\end{array}$ & & & $\mathrm{Plb}$ \\
\hline & & Sex, during & Cact & Arg-n & $\begin{array}{l}\text { Alumn, apis, bell, berb, bor, calc, calc-p, coff, ferr, ferr-m, } \\
\text { ferr-ma, gel, ham, hep, hydr, ign, kali-bi, kali-c, kreos, lyc, } \\
\text { lyss, merc, rhus-t, sabina, sil, sulph, thuj }\end{array}$ \\
\hline & & Sex, painful & $\begin{array}{l}\text { Arg-n, lyss, nat- } \\
\text { m, sep, staph }\end{array}$ & $\begin{array}{l}\text { Berb, calc-p, ferr, } \\
\text { ferr-m, ferr-ma, } \\
\text { hep, kali-bi, kali-c, } \\
\text { kreos, lyc, plat, } \\
\text { rhus-t, sulph, thuj }\end{array}$ & $\begin{array}{l}\text { Alumn, apis, bell, bor, calc, coff, ham, hydr, ign, merc, } \\
\text { sabina, sil }\end{array}$ \\
\hline & & Sex, preventing & Cact, staph & Plat & cupr \\
\hline
\end{tabular}

Table 1: Homoeopathic clinical repertory by Robin Murphy

\begin{tabular}{|l|c|c|c|c|c|}
\hline Chapter & Rubric & Sub rubric & $\begin{array}{c}\mathbf{1}^{\text {st }} \text { grade } \\
\text { remedies }\end{array}$ & $\mathbf{2}^{\text {nd }}$ grade remedies & $\mathbf{3}^{\text {rd }}$ grade remedies \\
\hline Female & vaginismus & & Cact, plb & $\begin{array}{c}\text { Acon, bell, berb, canth, ferr-p, ham, ign, lyc, } \\
\text { nat-m, puls, sil }\end{array}$ & $\begin{array}{c}\text { Cocc, ferr, gel, kali-br, mag-p, merc, nux-v, } \\
\text { plat }\end{array}$ \\
\hline & & $\begin{array}{c}\text { Coition, } \\
\text { during }\end{array}$ & & Plat & Cact \\
\hline & & Preventing & Cact & plat & \\
\hline
\end{tabular}

\section{Materia medica of Grade I remedies \\ - Cactus grandiflorus}

Mind- Melancholy, taciturn, sad, ill-humored, fear of death, screams with pain, anxiety.

Female- Constriction in uterine region and ovaries, dysmenorrhoea; pulsating pain in uterus and ovaries. Vaginismus. Menses early, dark, pitch-like (Cocc; Mag c); cease on lying down, with heart symptoms.

\section{- Cuprum metallicum}

Mind- Fixed ideas, malicious and morose, uses words not intended, fearful, empty feeling. Purple, red swelling of head, with convulsions.

Female- Menses too late, protracted, cramps, extending into chest, before, during or after suppression of menses. Also, from suppressed foot sweats (Sil). Ebullition of blood; palpitation. Chlorosis, after-pains.

\section{- Ignatia amara}

Mind- Changeable mood; introspective; silently brooding. melancholic, sad, tearful. After shocks, grief, disappointment. Not communicative.

Female- Menses, black, too early, too profuse, or scanty. During menses great languor, with spasmodic pains in stomach and abdomen. Feminine sexual frigidity. Suppression from grief.

\section{- Platinum metallicum}

Mind- Irresistible impulse to kill. Self-exaltation; contempt for others. Arrogant, proud. Weary of everything. Everything seems changed. Mental trouble pressed menses. Physical symptoms disappear as mental symptoms develop. Female- Parts hypersensitive, tingling internally and externally (Kali brom; Orig). Ovaries sensitive and burn. Menses too early, too profuse, dark-clotted, with spasms and painful bearing-down, chilliness, and sensitiveness of parts. Vaginismus. Nymphomania. Excessive sexual development; vaginismus. Pruritus vulvæ. Ovaritis with sterility. Abnormal sexual appetite and melancholia.

\section{- Plumbum metallicum}

Mind- Mental depression. Fear of being assassinated. Quiet melancholy. Slow perception; loss of memory; amnesic aphasia. Hallucinations and delusions. Intellectual apathy. Memory impaired (Anac; Baryta). Paretic dementia.

Female- Vaginismus, with emaciation and constipation. Induration of mammary glands. Vulva and vagina hypersensitive. Stitches and burning pains in breasts (Apis; Con; Carb an; Sil). Tendency to abortion. Menorrhagia with sensation of string pulling from abdomen to back. Disposition to yawn and stretch.

\section{- Staphysagria}

Mind- Impetuous, violent outbursts of passion, hypochondrial, sad. Very sensitive as to what others say about her. Dwells on sexual matters; prefers solitude. Peevish. Child cries for many things, and refuses them when offered.

Female- Parts very sensitive, worse sitting down (Berb; Kreos). Irritable bladder in young married women. Leucorrhoea. Prolapse, with sinking in the abdomen; aching around the hips.

\section{- Argentum nitricum}

Mind- Thinks his understanding will and must fail. Fearful and nervous; impulse to jump out of window. Faintish and 
tremulous. Melancholic; apprehensive of serious disease. Time passes slowly (Cann ind). Memory weak. Errors of perception. Impulsive; wants to do things in a hurry (Lilium). Peculiar mental impulses. Fears and anxieties and hidden irrational motives for actions.

Female- Gastralgia at beginning of menses. Intense spasm of chest muscles. Organs at night. Nervous erethism at change of life. Leucorrhoea profuse, with erosion of cervix bleeding easily. Uterine haemorrhage, two weeks after menses; Painful affections of left ovary.

\section{- Lyssinum}

Mind- Lyssophobia; fear of becoming mad. Emotion and bad news aggravate; also, thinking of fluids. Hypersensitiveness of all senses.

Female- Uterine sensitiveness; conscious of womb (Helon). Feels prolapsed. Vagina sensitive, rendering coition painful (Berberis). Uterine displacements.

\section{- Natrium muriaticum}

Mind- Psychic causes of disease; ill effects of grief, fright, anger, etc. Depressed, particularly in chronic diseases. Consolation aggravates. Irritable; gets into a passion about trifles. Awkward, hasty. Wants to be alone to cry. Tears with laughter.

Female- Menses irregular; usually profuse. Vagina dry. Leucorrhoea acrid, watery. Bearing-down pains; worse in morning (Sep). Prolapse uteri, with cutting in urethra. Ineffectual labor-pains. Suppressed menses (Follow with Kali carb). Hot during menses.

\section{- Sepia officinalis}

Mind- Indifferent to those loved best. Averse to occupation, to family. Irritable; easily offended. Dreads to be alone. Very sad, weeps when telling symptoms. Miserly, anxious toward evening; indolent.

Female- Pelvic organs relaxed. Bearing-down sensation as if everything would escape through vulva (Bell; Kreos; Lac C; Lil T; Nat C; Pod); must cross limbs to prevent protrusion, or press against vulva. Leucorrhoea yellow, greenish; with much itching. Menses Too late and scanty, irregular; early and profuse; sharp clutching pains. Violent stitches upward in the vagina, from uterus to umbilicus. Prolapse of uterus and vagina. Morning sickness. Vagina painful, especially on coition.

\section{Materia medica of Grade II remedies \\ - Aconitum napellus}

Mind- Great fear, anxiety, and worry accompany every ailment, however trivial. Delirium is characterized by unhappiness worry, fear, raving, rarely unconsciousness. Forebodings and fears. Fears death but believes that he will soon die; predicts the day. Fears the future, a crowd, crossing the street. Restlessness, tossing about. Tendency to start. Imagination acute, clairvoyance. Pains are intolerable; they drive him crazy. Music is unbearable; makes her sad (Ambra). Thinks his thoughts come from the stomach--that parts of his body are abnormally thick. Feels as if what had just been done was a dream.

Female- Vagina dry, hot, sensitive. Menses too profuse, with nosebleed, too protracted, late. Frenzy on appearance of menses. Suppressed from fright, cold, in plethoric subjects. Ovaries congested and painful. Sharp shooting pains in womb. After-pains, with fear and restlessness.

\section{- Belladonna}

Mind- Patient lives in a world of his own, engrossed by specters and visions and oblivious to surrounding realities. While the retina is insensible to actual objects, a host of visual hallucinations throng about him and come to him from within. He is acutely alive and crazed by a flood of subjective visual impressions and fantastic illusions. Hallucinations; sees monsters, hideous faces. Delirium; frightful images; furious; rages, bites, strikes; desire to escape. Loss of consciousness. Disinclined to talk. Perversity, with tears. Acuteness of all senses. Changeableness.

Female- Sensitive forcing downwards, as if all the viscera would protrude at genitals. Dryness and heat of vagina. Dragging around loins. Pain in sacrum. Menses increased; bright red, too early, too profuse. Haemorrhage hot. Cutting pain from hip to hip. Menses and lochia very offensive and hot. Labor-pains come and go suddenly. Mastitis pain, throbbing, redness, streaks radiate from nipple. Breasts feel heavy; are hard and red. Tumors of breast, pain worse lying down. Badly smelling haemorrhages, hot gushes of blood. Diminished lochia.

\section{- Berberis vulgaris}

Mind- Listless, apathetic, indifferent. Puffy sensation, feeling as if becoming larger.

Female- Pinching constriction in mons veneris, vaginismus, contraction and tenderness of vagina. Burning and soreness in vagina. Desire diminished, cutting pain during coition. Menses scanty, gray mucus, with pain in kidneys and chilliness, pain down thighs. Leucorrhoea, grayish mucus, with painful urinary symptoms. Neuralgia of ovaries and vagina.

\section{- Cantharis vesicatoria}

Mind- Furious delirium. Anxious restlessness, ending in rage. Crying, barking; worse touching larynx or drinking water. Constantly attempts to do something, but accomplishes nothing. Acute mania, generally of a sexual type; amorous frenzy; fiery sexual desire. Paroxysms of rage, crying, barking. Sudden loss of consciousness with red face.

Female- Retained placenta (Sep), with painful urination. Expels moles, dead f́stuses, membranes, etc. Nymphomania (Plat; Hyos; Lach; Stram). Puerperal metritis, with inflammation of bladder. Menses too early and too profuse; black swelling of vulva with irritation. Constant discharge from uterus; worse false step. Burning pain in ovaries; extremely sensitive. Pain in os coccyx, lancinating and tearing.

\section{- Caulophyllum thalictroides}

Female- Extraordinary rigidity of os (Bell; Gels; Ver v). Spasmodic and severe pains, which fly in all directions; shivering, without progress; false pains. Revives labor pains and furthers progress of labor. After pains. Leucorrhoea, with moth-spots on forehead. Habitual abortion from uterine debility (Helon; Puls; Sab). Needle-like pains in cervix. Dysmenorrhea, with pains flying to other parts of body. Lochia protracted; great atony. Menses and leucorrhoea profuse. 


\section{- Cimicifuga racemosa}

Mind- Sensation of a cloud enveloping her. Great depression, with dream of impending evil. Fears riding in a closed carriage, of being obliged to jump out. Incessant talking. Visions of rats, mice, etc. Delirium tremens; tries to injure himself. Mania following disappearance of neuralgia. Female- Amenorrhea. Pain in ovarian region; shoots upward and down anterior surface of thighs. Pain immediately before menses. Menses profuse, dark, coagulated, offensive with backache, nervousness; always irregular. Ovarian neuralgia. Pain across pelvis, from hip to hip. After-pains, with great sensitiveness and intolerance to pain. Infra-mammary pains worse, left side. Facial blemishes in young women.

\section{- Coffea cruda}

Mind- Gaiety, easy comprehension, irritability, excited; senses acute. Impressionable, especially to pleasurable impressions. Full of ideas, quick to act. Tossing about in anguish (Acon).

Female- Menses too early and long lasting. Dysmenorrhoea, large clots of black blood. Hypersensitive vulva and vagina. Voluptuous itching.

\section{- Ferrum phosphoricum}

Female- Menses every three weeks, with bearing-down sensation and pain on top of head. Vaginismus. Vagina dry and hot.

\section{- Hamamelis virginiana}

Female- Ovarian congestion and neuralgia; feel very sore. Vicarious menstruation. Uterine haemorrhage, bearingdown pain in back. Menses dark, profuse, with soreness in abdomen. Metorrhagia, occurring midway between menstrual periods. Intermenstrual pain (Jas. W. Ward). Vagina very tender. Profuse leucorrhoea. Vulva itches. Milk-leg, hemorrhoids, and sore nipples, after confinement. Metorrhagia; passive flow. Vaginismus, ovaritis, soreness over whole abdomen. Phlegmasia alba.

\section{- Lycopodium clavatum}

Mind- Melancholy; afraid to be alone. Little things annoy, Extremely sensitive. Averse to undertaking new things. Head strong and haughty when sick. Loss of selfconfidence. Hurried when eating. Constant fear of breaking down under stress. Apprehensive. Weak memory, confused thoughts; spells or writes wrong words and syllables. Failing brain-power (Anac; Phos; Baryt). Cannot bear to see anything new. Cannot read what he writes. Sadness in morning on awaking.

Female- Menses too late; last too long, too profuse. Vagina dry. Coition painful. Right ovarian pain. Varicose veins of pudenda. Leucorrhoea, acrid, with burning in vagina. Discharge of blood from genitals during stool.

\section{- Murex purpurea}

Mind- Great sadness, anxiety, and dread.

Female- Conscious of a womb. Pulsation in neck of womb. Desire easily excited. Feeling as if something was pressing on a sore spot in the pelvis: worse sitting. Pain from right side of womb to right or left breast. Nymphomania. Least contact of parts causes violent sexual excitement. Sore pain in uterus. Menses irregular, profuse, frequent, large clots. Feeling of protrusion. Prolapse; enlargement of uterus, with pelvic tenesmus and sharp pains, extending toward breasts; aggravated lying down. Dysmenorrhoea and chronic endometritis, with displacement. Must keep legs tightly crossed. Leucorrhoea green or bloody, alternate with mental symptoms and aching in sacrum. Benign tumors in breasts. Pain in them during menstrual period.

\section{- Pulsatilla pratensis}

Mind- Weeps easily. Timid, irresolute. Fears in evening to be alone, dark, ghost. Likes sympathy. Children like fuss and caresses. Easily discouraged. Morbid dread of the opposite sex. Religious melancholy. Given to extremes of pleasure and pain. Highly emotional. Mentally, an April day.

Female- Amenorrhea (Cimicif; Senec; Polygon). Suppressed menses from wet feet, nervous debility, or chlorosis. Tardy menses. Too late, scanty, thick, dark, clotted, changeable, intermittent. Chilliness, nausea, downward pressure, painful, flow intermits. Leucorrhoea acrid, burning, creamy. Pain in back; tired feeling. Diarrhoea during or after menses.

\section{- Calcarea phosphorica}

Mind- Peevish, forgetful; after grief and vexation (Ignat; Phos ac). Always wants to go somewhere.

Female- Menses too early, excessive, and bright in girls. If late, blood is dark; sometimes, first bright, then dark, with violent backache. During lactation with sexual excitement. Nymphomania, with aching, pressing, or weakness in uterine region (Plat). After prolonged nursing. Leucorrhoea, like white of egg. Worse morning. Child refuses breast; milk tastes salty. Prolapse in debilitated persons.

\section{- Ferrum metallicum}

Mind- Irritability. Slight noises unbearable. Excited from slightest opposition. Sanguine temperament.

Female- Menses remit a day or two, and then return. Discharge of long pieces from uterus. Women who are weak, delicate, chlorotic, yet have a fiery-red face. Menses too early, too profuse, last too long; pale, watery. Sensitive vagina. Tendency to abortion. Prolapse of vagina.

\section{- Hepar sulphur}

Mind- Anguish in the evening and night, with thoughts of suicide. The slightest cause irritates him. Dejected and sad. Ferocious. Hasty speech.

Female- Discharge of blood from uterus. Itching of pudenda and nipples, worse during menses. Menses late and scanty. Abscesses of labia with great sensitiveness. Extremely offensive leucorrhoea. Smells like old cheese (Sanicula). Profuse perspiration at the climacteric (Tilia; Jaborandi).

\section{- Kalium bichromicum}

Female- Yellow, tenacious leucorrhoea. Pruritus of vulva, with great burning and excitement. Prolaps uteri; worse in hot weather.

\section{- Kalium carbonicum}

Mind- Despondent. Alternating moods. Very irritable. Full of fear and imaginations. Anxiety felt in stomach. Sensation as if bed were sinking. Never wants to be left alone. Never quiet or contented. Obstinate and hypersensitive to pain, 
noise, touch.

Female- Menses early, profuse (Calc C) or too late, pale and scanty, with soreness about genitals; pains from back pass down through gluteal muscles, with cutting in abdomen. Pain through left labium, extending through abdomen to chest. Delayed menses in young girls, with chest symptoms or ascites. Difficult, first menses. Complaints after parturition. Uterine haemorrhage; constant oozing after copious flow, with violent backache, relieved by sitting and pressure.

\section{- Kreosotum}

Mental- Music causes weeping and palpitation. Vanishing of thought; stupid, forgetful, peevish, irritable. Child wants everything but throws it away when given.

Female- Corrosive itching within vulva, burning and swelling of labia; violent itching between labia and thighs. During menses, difficult hearing; buzzing and roaring; eruption after. Burning and soreness in external and internal parts. Leucorrhoea, yellow, acrid; odor of green corn; worse between periods. Haemorrhage after coition. Menses too early, prolonged. Vomiting of pregnancy, with ptyalism. Menstrual flow intermits (Puls); ceases on sitting or walking; reappears on lying down. Pain worse after menses. Lochia offensive; intermits.

\section{- Rhus toxicodendron}

Mind- Listless, sad. Thoughts of suicide. Extreme restlessness, with continued change of position. Delirium, with fear of being poisoned (Hyos). Sensorium becomes cloudy. Great apprehension at night, cannot remain in bed.

Female- Swelling, with intense itching of vulva. Pelvic articulations stiff when beginning to move. Menses early, profuse and prolonged, acrid. Lochia thin, protracted, offensive diminished (Puls; Secale), with shooting upwards in vagina (Sep).

\section{- Sulphur}

Mind- Very forgetful. Difficult thinking. Delusions; thinks rags beautiful things-that he is immensely wealthy. Busy all the time. Childish peevishness in grown people. Irritable. Affections vitiated; very selfish, no regard for others. Religious melancholy. Averse to business; loafs-too lazy to arouse himself. Imagining giving wrong things to people, causing their death. Sulphur subjects are nearly always irritable, depressed, thin and weak, even with good appetite. Female- Pudenda itches. Vagina burns. Much offensive perspiration. Menses too late, short, scanty, and difficult; thick, black, acrid, making parts sore. Menses preceded by headache or suddenly stopped. Leucorrhoea, burning, excoriating. Nipples cracked; smart and burn.

\section{- Thuja occidentalis}

Mind- Fixed ideas, as if a strange person were at his side; as if soul and body were separated; as if something alive in abdomen (Croc). Emotional sensitiveness; music causes weeping and trembling.

Female- Vagina very sensitive (Berb; Kreos; Lyssin). Warty excrescences on vulva and perineum. Profuse leucorrhoea; thick, greenish. Severe pain in left ovary and left inguinal region. Menses scanty, retarded. Polypi; fleshy excrescences. Ovaritis; worse left side, at every menstrual period (Lach). Profuse perspiration before menses.

\section{- Silicea terra}

Mind- Yielding, faint-hearted, anxious. Nervous and excitable. Sensitive to all impressions. Brain-fag. Obstinate, headstrong children. Abstracted. Fixed ideas; thinks only of pins, fears them, searches and counts them.

Female- A milky (Calc; Puls; Sep), acrid leucorrhoea, during urination. Itching of vulva and vagina; very sensitive. Discharge of blood between menstrual periods. Increased menses, with paroxysms of icy coldness over whole body. Nipples very sore; ulcerated easily; drawn in. Fistulous ulcers of breast (Phos). Abscess of labia. Discharge of blood from vagina every time child is nursed. Vaginal cysts (Lyc; Puls; Rhod) hard lumps in breast (conium).

\section{References}

1. Homoeopathic Materia Medica by William Boericke.

2. Shaw's textbook of gynecology $16 \mathrm{ed} 2015$.

3. Dc Dutta's textbook of gynecology.

4. Repertory of the homoeopathic materia medica by JT Kent.

5. Homoeopathic clinical repertory by Robin Murphy.

6. Dewhurst's textbook of obstetrics and gynaecology.

7. Textbook of materia medica by Dr. SK Dubey.

8. Textbook of gynaecology and obstetrics by Dr. Balaram Jana.

9. Vaginismus as a hidden problem: Our case series, International Journal of Advanced Studies in Sexology 2021;3(1):5-9. DOI: 10.46388/ijass.2020.13.32

10. Anita Lobo, Prema D'cunha, Blany Lobo. Effectiveness of homoeopathic treatment in female, Infertility Reproductive Medicine International 2018;1(2). DOI:2018, 1:008.

11. Katole A, Saoji AV. Prevalence of primary infertility and its associated risk factors in urban population of central India: A community-based cross-sectional study, Indian J Community med DOI: 2019;44:337-41.

12. Tourneur-Bagot, Odile, Bagot, Jean-lionel. Vaginismus- The gynaecologist and the homeopath: converging perspectives. La revue d'homéopathie. 6. E7-e10 2015. DOI: 10.1016/j.revhom.2015.07.012.

13. Dr. Shaila Udachankar M, Dr. Prasad Daddikar, Dr. Anita S Patil, Dr. DV Gizare. "Role of homoeopathy in unexplained infertility", Ijrar - international journal of research and analytical reviews (Ijrar), e-issn 23481269, p-issn 2349-5138 2018;5(4):7-17.

14. Dr. Padmalaya Rath. A case of infertility due to pcos treated successfully with homoeopathy, International journal of homoeopathic sciences 2020;4(2):249-260.

15. Bianca De Canha. The homoeopathic similimum and infertility of unexplained causes in females, a research dissertation presented to the faculty of health sciences, university of johnnesburg in partial fulfillment of the master degree in technology: homoeopathy 2009.

16. Rath P. Management of PCOS through homoeopathy-a case report, Indian j res homoeopathy 2018;12:95-100. 